\title{
Propofol and arrhythmias: two sides of the coin
}

\author{
Qiang LIU ${ }^{1}$, Ai-ling KONG ${ }^{1,}$, Rong CHEN ${ }^{1}$, Cheng QIAN ${ }^{1}$, Shao-wen LIU ${ }^{1}$, Bao-gui SUN ${ }^{1}$, Le-xin WANG ${ }^{2}$, Long-sheng SONG ${ }^{3}$, \\ Jiang $\mathrm{HONG}^{1, *}$ \\ ${ }^{1}$ Department of Cardiology, Shanghai First People's Hospital, School of Medicine, Shanghai Jiaotong University, Shanghai 200080, \\ China; ${ }^{2}$ School of Biomedical Sciences, Charles Sturt University, Wagga Wagga, NSW, Australia; ${ }^{3}$ Division of Cardiology, Department of \\ Internal Medicine, University of lowa College of Medicine, lowa City, IA, USA
}

\begin{abstract}
The hypnotic agent propofol is effective for the induction and maintenance of anesthesia. However, recent studies have shown that propofol administration is related to arrhythmias. Propofol displays both pro- and anti-arrhythmic effects in a concentration-dependent manner. Data indicate that propofol can convert supraventricular tachycardia and ventricular tachycardia and may inhibit the conduction system of the heart. The mechanism of the cardiac effects remains poorly defined and may involve ion channels, the autonomic nervous system and cardiac gap junctions. Specifically, sodium, calcium and potassium currents in cardiac cells are suppressed by clinically relevant concentrations of propofol. Propofol shortens the action potential duration (APD) but lessens the ischemia-induced decrease in the APD. Furthermore, propofol suppresses both sympathetic and parasympathetic tone and preserves gap junctions during ischemia. All of these effects cumulatively contribute to the antiarrhythmic and proarrhythmic properties of propofol.
\end{abstract}

Keywords: propofol; arrhythmias; ion channels; gap junction; autonomic nervous system

Acta Pharmacologica Sinica (2011) 32: 817-823; doi: 10.1038/aps.2011.42

\section{Introduction}

The hypnotic agent propofol (2,6-diisopropylphenyl) is widely used during the induction and maintenance of anesthesia. It has the advantages of minimal side effects, a controllable anesthetic state, a quick onset, and rapid patient emergence from general anesthesia. Apart from these anesthetic properties, propofol has additional antiarrhythmic and proarrhythmic effects.

\section{Antiarrhythmic property of propofol}

Several case reports have documented the antiarrhythmic effects of propofol. Kannan and Sherwood ${ }^{[1]}$ reported that a 68-year-old man with a previous myocardial infarction experienced supraventricular tachycardia. In this patient, administration of adenosine or carotid sinus massage had no effect, but propofol converted the supraventricular arrhythmia to sinus rhythm before electrical cardioversion. Hermann and Vettermann reported another case of ectopic supraventricular tachycardia that was terminated by propofol ${ }^{[2]}$. Propofol has also been shown to terminate ventricular tachycardia (VT)

\footnotetext{
$\S$ Now in Department of Cardiology, Yancheng First People's Hospital, Yancheng, China

* To whom correspondence should be addressed.

E-mail jhong.pku@163.com

Received 2011-02-16 Accepted 2011-04-07
}

storm $^{[3,4]}$. Burjorjee and Milne reported that propofol resolved the recurrent episodes of VT that were not terminated by maximal antiarrhythmic therapy in a 65-year-old $\operatorname{man}^{[3]}$; similar results were observed in a second study of a patient with comparable disease ${ }^{[4]}$.

Additionally, propofol converted atrial fibrillation, which was not terminated by intravenous infusion of amiodarone, to sinus rhythm ${ }^{[5]}$. Propofol can significantly decrease P-wave dispersion ${ }^{[6]}$, which may represent the reason for termination of atrial fibrillation. Furthermore, propofol may improve cardiac conduction. After propofol injection, the delta wave of Wolff-Parkinson-White syndrome has been shown to disappear and the P-R interval to normalize, though the delta wave returned immediately after propofol discontinuation ${ }^{[7,8]}$. The Q-T interval of long Q-T syndrome was shortened when propofol was used; therefore, propofol may have the potential to prevent episodes of VT that are due to Q-T interval disper$\operatorname{sion}^{[9,10]}$.

Reperfusion of the heart after short-term ischemia may lead to potentially lethal arrhythmias, but propofol can alleviate reperfusion-induced arrhythmia. In the isolated rat myocardium, propofol had antiarrhythmic effects against reperfusioninduced arrhythmia at concentrations of 1,10 , and $20 \mu \mathrm{mol} / \mathrm{L}$, and the incidence and duration of sustained arrhythmias were decreased significantly ${ }^{[11]}$. From the above studies, we conclude that propofol is likely to inhibit arrhythmias. How- 
ever, clinical conditions are often complex, and the general classification of propofol as a unique agent for antiarrhythmic therapy cannot yet be made. Thus, more studies are needed to understand the detailed mechanism by which propofol exerts its antiarrhythmic effects.

\section{Proarrhythmic properties of propofol}

Some studies have demonstrated that propofol has the potential to block the conduction system of the heart and thereby induce arrhythmia. A study of 60 children with paroxysmal supraventricular tachycardia undergoing radiofrequency catheter ablation showed that atrioventricular (AV) node (AVN) conduction was slowed with propofol ${ }^{[12]}$. Atrial wavelength and AVN are electrophysiologic factors critical to the pathogenesis of supraventricular tachydysrhythmias. A study focusing on the effects of anesthetics on such electrophysiologic factors in guinea pig hearts has indicated that propofol does not change the atrial wavelength. However, this study revealed that propofol prolonged the AVN effective refractory period (ERP) in concentration- and frequency-dependent manners, though no significant effect on atrial conduction velocity was detected ${ }^{[13]}$. Additionally, at concentrations greater than $25 \mu \mathrm{mol} / \mathrm{L}$, propofol slowed the atrial rate and AVN conduction and prolonged the Wenckebach cycle length in a concentration-dependent manner. The frequency of propofol administration also correlated with stimulus-to-His bundle intervals, such that the higher the frequency, the longer the S-H interval ${ }^{[14]}$.

Propofol $(3 \mu \mathrm{mol} / \mathrm{L})$ significantly prolonged the rabbit AV conduction interval in a dose-dependent (3 to $100 \mu \mathrm{mol} / \mathrm{L}$ ) manner. At higher concentrations (10 to $100 \mu \mathrm{mol} / \mathrm{L}$ ), the AVN Wenckebach cycle length and its refractory period were also prolonged. In addition, conduction through the HisPurkinje system (HV interval) and the atrial tissue (SA interval), as well as the spontaneous cycle length, were lengthened in a dose-dependent manner (30 to $100 \mu \mathrm{mol} / \mathrm{L}$ ). By contrast, propofol had no effect on the refractory period of the atrium, ventricle, or the His-Purkinje system ${ }^{[15]}$. Therefore, propofol inhibits AV conduction in a concentration-dependent fashion.

Conversely, some research suggests that propofol does not affect the conduction system. For example, propofol had no effect on the electrophysiological properties of the AVN and pathway conduction in atrioventricular nodal reentrant tachycardia patients ${ }^{[16]}$. Additionally, propofol did not cause sinoatrial node depression or a pathological increase in atrioventricular conduction ${ }^{[17]}$. Studies in normal pig hearts demonstrate that propofol promotes a dose-related depression of sinus node and His-Purkinje system functions but has no effect on the AVN function or the conduction properties of atrial and ventricular tissues ${ }^{[18]}$

The effects of propofol on the conduction system may be impacted by age and drug concentration. At a low concentration $(3 \mu \mathrm{mol} / \mathrm{L})$, propofol induced a significant lengthening of the AV conduction interval in adult rabbit hearts but not neonatal hearts. At a higher concentration $(10 \mu \mathrm{mol} / \mathrm{L}$ and above), propofol significantly prolonged the AV conduction interval in hearts from both neonates and adults. The AV Wenckebach cycle length was also lengthened, with a more significant change in the adult hearts. However, with concentrations of propofol up to $100 \mu \mathrm{mol} / \mathrm{L}$, the neonatal hearts progressed to complete AV block, which did not occur in the adults. The spontaneous heart rate and conduction through the atrial tissue (SA interval) and the His-Purkinje system (HV interval) were all slowed by propofol at $30 \mu \mathrm{mol} / \mathrm{L}$ or above. Additionally, the lengthening of the SA interval was more pronounced in the neonatal hearts, where the atrial refractory period was prolonged by propofol at $10 \mu \mathrm{mol} / \mathrm{L}$ and above ${ }^{[19]}$.

Based on the above study, the effects of propofol on the conduction system remain controversial. One reasonable explanation is that different concentrations promote divergent effects: at clinically relevant or low concentrations, propofol does not significantly suppress conduction, but at high concentrations, it blocks conduction.

In a canine study, propofol reduced the arrhythmogenic plasma concentration of epinephrine in a concentrationdependent manner, which suggests that propofol enhances epinephrine-induced arrhythmias ${ }^{[20]}$. Furthermore, propofol can directly induce arrhythmia.

Rewari and Kaul ${ }^{[21]}$ have reported that one long Q-T interval syndrome patient undergoing surgery experienced ventricular premature beats immediately upon propofol administration and then progressed to polymorphic ventricular tachycardia that intermittently changed to ventricular fibrillation. Another report described a 78-year-old woman with normal cardiac function who suffered torsade de pointes and then progressed to ventricular fibrillation after propofol infusion ${ }^{[22]}$. Prolonged high-dose propofol infusion can induce some particular arrhythmias. An infant also developed dramatic cardiac conduction disturbances and tachyarrhythmias after prolonged high-dose propofol infusion; this patient's electrocardiograph resembled that of a patient with Brugada syndrome ${ }^{[23]}$. A study of a chronic propofol abuser with a propofol blood concentration as high as $0.73 \mu \mathrm{g} / \mathrm{g}$ also revealed a Brugadalike electrocardiograph. This patient subsequently developed a long Q-T interval, idioventricular rhythm, and ventricular fibrillation $^{[24]}$.

These cases demonstrate that propofol can block conduction and induce bradycardia. Polymorphic ventricular tachycardia and some particular arrhythmias similar to Brugada syndrome can also result from propofol treatment. It should be noted that the most common abnormality is bradycardia, whereas others, such as AV block, are relatively rare and only occur at high propofol concentrations. A systematic review showed that the incidence of bradycardia ( $<50$ beats per minute) was $4.8 \%$ in the presence of propofol ${ }^{[25]}$. The reason for the conduction block could be the ability of propofol to modify the activity of human atrial muscarinic cholinergic receptors, and this effect may be related to the drug-induced bradycardia ${ }^{[26]}$. Further, an M-2-muscarinic receptor-mediated mechanism may be the reason for propofol-induced conduction block. In a study of isolated guinea pig hearts, the negative dromotropic effect of propofol was attenuated by a muscarinic receptor 
$\operatorname{antagonist}^{[14]}$.

\section{Propofol and action potential duration}

Action potential duration (APD) is determined by several inward and outward ion currents, including $I_{\mathrm{Na}}, I_{\mathrm{Ca}}, I_{\mathrm{KR}}$, and $I_{\mathrm{KS}}$. Changes in any individual current may prolong or shorten the APD, and APD dispersion can produce ventricular arrhythmia. Propofol (25 and $50 \mu \mathrm{mol} / \mathrm{L})$ shortened monophasic APD at $90 \%$ repolarization $\left(\mathrm{MAPD}_{90}\right)$ in Langendorffperfused guinea pig hearts ${ }^{[27]}$. With single guinea pig cardiac myocytes, propofol (10 and $100 \mu \mathrm{mol} / \mathrm{L})$ shortened the APD. A concentration-dependent shortening of the APD was produced by propofol $(1-100 \mu \mathrm{mol} / \mathrm{L})$ in these cells ${ }^{[28]}$. However, the concentration of propofol required to reduce the APD by $50 \%$ was at least $100 \mu \mathrm{mol} / \mathrm{L}$, and neither resting membrane potential nor action potential amplitude was significantly affected $^{[29]}$. High-dose propofol $(1000 \mu \mathrm{mol} / \mathrm{L})$ also shortened the APD of single dog ventricular cells ${ }^{[30]}$. Propofol reduced the $\mathrm{APD}_{20}$ and the $\mathrm{APD}_{90}$ (the time required for $20 \%$ or $90 \%$ repolarization, respectively) in guinea pig cardiomyocytes in a concentration-dependent manner, and the $\mathrm{APD}_{90}$ was reduced by $21 \%$ at $100 \mu \mathrm{mol} / \mathrm{L}^{[31]}$. In seeming contrast, however, propofol lessened the ischemia-induced decrease in the $\mathrm{APD}_{90}$ at $1 \mu \mathrm{mol} / \mathrm{L}$ and $10 \mu \mathrm{mol} / \mathrm{L}$ and attenuated the APD dispersion around the "border zone", which is between the normal and ischemic zones of guinea pig right ventricular muscle strips. Specifically, the APD was shortened by $27 \%, 31 \%$ and $3 \%$ at doses of 1,10 , and $20 \mu \mathrm{mol} / \mathrm{L}$ propofol, respectively ${ }^{[11]}$. This effect is of particular importance because the decrease in APD dispersion between the normal and ischemic areas results in a reduction in the incidence of reentrant tachycardia. These paradoxical findings indicate that the propofol-induced shortening or prolongation of the APD is related to the cell surroundings. In normal conditions, propofol reduces the $\mathrm{APD}$, whereas in ischemic conditions, it lessens the shortening trend.

\section{Propofol and ion channels}

Propofol can influence some ion currents, including the ATPsensitive potassium current, delayed rectifier $\mathrm{K}^{+}$current, transient outward rectifier $\mathrm{K}^{+}$channel current, inward rectifier $\mathrm{K}^{+}$current, sodium current, and L-type $\mathrm{Ca}^{2+}$ current. These effects cumulatively result in changes to the APD.

ATP-sensitive potassium channels $\left(\mathrm{K}_{\mathrm{ATP}}\right)$, which are composed of the Kir6.x and SUR subunits, are regulated by cytosolic nucleotides and link cell metabolism to electrical activity and $\mathrm{K}^{+}$fluxes. There are two types: sarcolemmal $\mathrm{K}_{\mathrm{ATP}}$ ( sarcK $\left._{\text {ATP }}\right)$ channels and mitochondrial $K_{\text {ATP }}\left(\right.$ mitoK $\left._{\text {ATP }}\right)$ channels. A number of studies have examined the effect of propofol on mitoK $\mathrm{ATP}_{\mathrm{AT}}$ channels.

In isolated guinea pig myocardial cells, propofol alone had no significant effects on mitoK $\mathrm{K}_{\mathrm{ATP}}$ channels at a concentration of $50 \mu \mathrm{mol} / \mathrm{L}$, but it dose-dependently inhibited isofluraneinduced mitochondrial $\mathrm{K}_{\mathrm{ATP}}$ channel opening ${ }^{[32]}$. In isolated ischemia-reperfused guinea pig hearts, propofol $(35 \mu \mathrm{mol} / \mathrm{L})$ had no effect on mitoK ${ }_{\text {ATP }}$ channels ${ }^{[33]}$. A study of single rat ventricular myocytes showed that propofol inhibited mitoK $\mathrm{ATP}_{\text {ATP }}$ channel activity, but the concentration required was very high $(>31 \mu \mathrm{mol} / \mathrm{L})^{[34]}$. By contrast, propofol has differing effects on sarcK $_{\text {ATP }}$ channels. For example, studies ${ }^{[35,36]}$ on recombinant cardiac sarcK $\mathrm{K}_{\text {ATP }}$ channels showed that propofol inhibited the channel with half the maximal inhibitory concentration $\left(\mathrm{IC}_{50}\right)$ more than $70 \mu \mathrm{mol} / \mathrm{L}$; in the presence of $\mathrm{MgADP}$, the $\mathrm{IC}_{50}$ was as high as $183 \mu \mathrm{mol} / \mathrm{L}$.

Because propofol protein binding exceeds $95 \%$, free fractions of propofol are less than $2 \mu \mathrm{mol} / \mathrm{L}^{[34]}$. Hence, we can conclude that propofol inhibits $\mathrm{K}_{\mathrm{ATP}}$ channels only at high concentrations and has no significant effect on either sarcK $\mathrm{K}_{\mathrm{ATP}}$ or mitoK $\mathrm{K}_{\mathrm{ATP}}$ channel activities at clinically relevant concentrations.

In the human heart, the delayed rectifier $\mathrm{K}^{+}$current $\left(I_{\mathrm{K}}\right)$ can be separated into at least three different components: ultrarapid $\left(I_{\mathrm{KUR}}\right)$, rapid $\left(I_{\mathrm{KR}}\right)$ and slow $\left(I_{\mathrm{KS}}\right)$. The effects of low- and high-dose propofol on some of these components have been examined. Two independent studies assessed the effect of propofol treatment on $I_{K}{ }^{[31,37]}$. In one, propofol $(28 \mu \mathrm{mol} / \mathrm{L})$ induced significant depression of the $I_{\mathrm{K}}$ component in single dispersed guinea pig ventricular myocytes. Data from the second study indicates that propofol inhibits $I_{\mathrm{K}}$ at a concentration of $50 \mu \mathrm{mol} / \mathrm{L}$. In another study, propofol suppressed the $I_{\mathrm{K}}$ amplitude in a concentration-dependent manner $\left(\mathrm{IC}_{50}=36\right.$ $\mu \mathrm{mol} / \mathrm{L}$ ) in differentiated $\mathrm{H} 9 \mathrm{c} 2$ cells. The $\mathrm{H} 9 \mathrm{c} 2$ cell line was established from an embryonic rat cardiac ventricle, and it has properties similar to neonatal and adult cardiomyocytes ${ }^{[38]}$. It is important to note that the concentrations required for $I_{\mathrm{K}}$ suppression are higher than what is currently used in the clinic.

The slowly activating component of the $I_{\mathrm{KS}}$ contributes to human atrium and ventricle repolarization, particularly during action potentials with a long duration, and is a dominant determinant of the physiological heart rate-dependent shortening of the $\mathrm{APD}^{[39]}$. A study of guinea pig ventricular myocytes indicated that propofol inhibited the $I_{\mathrm{KS}}\left(\mathrm{IC}_{50}=23 \mu \mathrm{mol} / \mathrm{L}\right)^{[29]}$, whereas data from another study in these cells demonstrated that propofol $(100 \mu \mathrm{mol} / \mathrm{L}$ and $300 \mu \mathrm{mol} / \mathrm{L})$ selectively inhibited the $I_{\mathrm{KS}}$ of isolated guinea pig ventricular myocytes. Therefore, propofol was preferred as the agent to separate $I_{\mathrm{K}}$ into $I_{\mathrm{KR}}$ and $I_{\mathrm{KS}}{ }^{[40]}$. Propofol also inhibited the $I_{\mathrm{sK}}\left(\mathrm{IC}_{50}=250 \mu \mathrm{mol} / \mathrm{L}\right)$, which is the current induced by the mRNA that encodes the minK protein that has similar electrophysiological properties to $I_{\mathrm{KS}}$. This particular study measured the channel activity after expression via injection into Xenopus oocytes ${ }^{[41]}$.

The rapid activating component of the delayed rectifier potassium current $\left(I_{\mathrm{KR}}\right)$ is characterized by rapid activation, rapid inactivation and strong inward rectification, which promotes phase 3 of repolarization. Thus, $I_{\mathrm{KR}}$ plays an important role in governing the cardiac APD and refractoriness. Pharmacologically, $I_{\mathrm{KR}}$ is the target of class III antiarrhythmic drugs; however, to the best of our knowledge, little research concerning the effects of propofol on the $I_{\mathrm{KR}}$ component has been published. Heath and Terrar ${ }^{[40]}$ showed that propofol had no effect on the channel, and it was selected as an agent 
to differentiate $I_{\mathrm{KR}}$ and $I_{\mathrm{KS}}$. Similarly, no group has reported how propofol modulates the ultrarapid activating component of the delayed rectifier potassium current $\left(I_{\mathrm{KUR}}\right)$, which exists only in human atria and not ventricular tissue. $I_{\mathrm{KUR}}$ is the predominant delayed rectifier current responsible for human atrial repolarization. Hence, studies of the effects of propofol on this component will be of great clinical value.

The transient outward rectifier $\mathrm{K}^{+}$channel current $\left(I_{\mathrm{to}}\right)$ is a voltage-gated channel current that is responsible for early rapid repolarization (phase 1). $I_{\mathrm{to}}$ also determines the height of the early plateau, thus influencing activation of other currents that control repolarization ${ }^{[31]}$. Propofol $(60 \mu \mathrm{mol} / \mathrm{L})$ inhibited the $I_{\text {to }}$ of canine ventricular cells, and the inhibition was not voltage dependent ${ }^{[42]}$. Propofol $(25$ and $50 \mu \mathrm{mol} / \mathrm{L})$ also significantly decreased the $I_{\text {to }}$ in rat ventricular myocytes but did not affect the voltage-dependent manner and the outward rectifier character ${ }^{[43]}$. In addition, the steady-state voltage-dependent inactivation curve of $I_{\text {to }}$ was shifted to a more negative membrane potential, and the $I_{\text {to }}$ of rabbit atrial myocytes was suppressed by propofol with a $50 \%$ effective dose $\left(\mathrm{ED}_{50}\right)$ of 5.7 $\mu \mathrm{mol} / \mathrm{L}$. At $3 \mu \mathrm{mol} / \mathrm{L}$, propofol slightly inhibited $I_{\mathrm{to}}$, suggesting that while propofol does inhibit $I_{\text {to }}$ at high concentrations, the suppression is minimal or nonexistent at clinically relevant concentrations $^{[15]}$.

The inward rectifier $\mathrm{K}^{+}$current $\left(I_{\mathrm{K} 1}\right)$ plays a significant role in cardiac myocytes where it maintains the resting membrane potential and shapes the late repolarization phase (phase 3) of the action potential. Whether propofol inhibits the $I_{\mathrm{K} 1}$ is not clear. Propofol $(28 \mu \mathrm{mol} / \mathrm{L})$ had no effect on the $I_{\mathrm{K} 1}$ of single dispersed guinea pig ventricular myocytes ${ }^{[37]}$ nor was an effect observed using a higher concentration $(60 \mu \mathrm{mol} / \mathrm{L})$ on single dispersed canine ventricular cells ${ }^{[42]}$. Further, propofol (2.5 $\mu \mathrm{mol} / \mathrm{L})$ did not alter $I_{\mathrm{K} 1}$ conductance in rat ventricular myocytes $^{[44]}$. By contrast, another study indicated that propofol suppressed $I_{\mathrm{K} 1}$, although the decrease in $I_{\mathrm{K} 1}$ occurred to a much lesser extent: the currents were decreased by only $18 \%$ when cells were exposed to $3 \mu \mathrm{mol} / \mathrm{L}$ propofol, and the inward rectification was not affected ${ }^{[15]}$.

Cardiac sodium channels transmit a large inward depolarizing current $\left(I_{\mathrm{Na}}\right)$ during phase 0 of the cardiac action potential, and it has been shown that propofol inhibits sodium currents. For example, in isolated rabbit ventricular myocytes, the $\mathrm{Na}^{+}$ current was decreased in dose-dependent and frequencydependent manners by propofol with an $\mathrm{ED}_{50}$ for current inhibition of $6.9 \mathrm{\mu mol} / \mathrm{L}$. In part, this suppression was due to a negative shift of the steady-state voltage-dependent inactivation and a decreased rate of recovery from inactivation ${ }^{[15]}$. Propofol inhibited $I_{\mathrm{Na}}$ in isolated rat myocardial cells, and the effect was enhanced at depolarized resting potentials ${ }^{[45]}$. In another study, single channel conductance was not changed by propofol, but a dose-dependent suppression of rat whole cell sodium currents $\left(\mathrm{ED}_{50}=14.8 \mu \mathrm{mol} / \mathrm{L}\right)$ was detected. The most reasonable explanation for this apparent dichotomy is that a shorter mean channel open time accompanied by an increased channel re-opening could result in slowed macroscopic inactivation $^{[46]}$. Hyperpolarization-activated, cyclic nucleotide- gated (HCN) channels conduct a monovalent cationic current Iff that contributes to autorhythmicity in the heart. Propofol inhibited and slowed the activation of recombinant HCN1, HCN2, and HCN4 channels at clinically relevant concentrations, in which the HCN1 current was the most sensitive of the three. HCN4 is the predominant subtype in the sinoatrial node (SA node ${ }^{[47,48]}$. In this study, HCN4 channel activation was decreased more significantly than other isoforms with $20 \mu \mathrm{mol} / \mathrm{L}$ propofol. In addition, propofol reduced the heart rate in an isolated guinea pig heart preparation over the same range of concentrations. These data indicate that propofol modulation of $\mathrm{HCN}$ channel gating is an important molecular mechanism that contributes to the bradyarrhythmic effect of propofol $^{[49]}$.

The L-type $\mathrm{Ca}^{2+}$ current $\left(I_{\mathrm{Ca}}\right)$ is important in heart function because it triggers excitation-contraction coupling, modulates action potential shape, and is involved in cardiac arrhythmia. The negative inotropic effect of propofol can therefore be best explained by inhibition of the L-type $\mathrm{Ca}^{2+}$ current $\left(I_{\mathrm{Ca}}\right)$. Though propofol did not alter steady-state $I_{\mathrm{Ca}}$ it reduced the isoproterenol-stimulated increase in $I_{\mathrm{Ca}}$ in a dose-dependent manner $(0.1-10 \mu \mathrm{mol} / \mathrm{L})^{[50]}$. Propofol caused a statistically significant decrease in the $I_{\mathrm{Ca}}$ of guinea pig cardiac myocytes in a concentration-dependent manner (1-100 $\mu \mathrm{mol} / \mathrm{L})$, even at low concentrations $(1 \mu \mathrm{mol} / \mathrm{L})^{[29]}$. In single dog ventricular cells, propofol decreased the $I_{\mathrm{Ca}}$ at $100 \mu \mathrm{mol} / \mathrm{L}^{[30]}$. Propofol $(10$ and $100 \mu \mathrm{mol} / \mathrm{L}$ ) also inhibited the $I_{\mathrm{Ca}}$ of $\mathrm{H} 9 \mathrm{c} 2$ cells and guinea pig cardiac myocytes ${ }^{[28,37]}$. In rat ventricular myocytes, propofol depressed the $I_{\mathrm{Ca}}$ by $28 \%$ and $57 \%$ at 25 and $50 \mu \mathrm{mol} / \mathrm{L}$, respectively ${ }^{[51]}$. These data from several different model systems definitively prove that propofol inhibits $I_{\mathrm{Ca}}$ even at concentrations used in the clinic $(1 \mu \mathrm{mol} / \mathrm{L})$.

In conclusion, propofol can inhibit sodium, calcium and potassium currents, but we should note that the concentrations needed for inhibition are much higher than clinically achievable concentrations. At clinically relevant concentrations, propofol is likely to inhibit $I_{\mathrm{K} 1}, I_{\mathrm{Na}}$ and $I_{\mathrm{Ca}}$. However, controversies still exist, most notably the fact that propofol shortened the APD but lessened the ischemia-induced decrease of the APD.

\section{Propofol and gap junctions}

Gap junctions comprise intercellular channels that couple cardiac myocytes electrically and metabolically by facilitating the intercellular exchange of ions, signaling molecules, and other molecular information between neighboring cells in the heart. The constituent proteins of gap junction channels, connexins, play a critical role in impulse propagation and electrical synchronization between myocytes. Multiple connexin types are expressed in the heart, among which connexin 43 (Cx43) is the principal gap junction protein in ventricular myocardium ${ }^{[52,53]}$.

Ventricular arrhythmia following acute myocardial infarction is always lethal. Propofol preconditioning has the ability to prevent the ischemic heart from progressing to a lethal ventricular arrhythmia. Cx43 is a principal cardiac gap-junction channel protein that undergoes progressive dephosphoryla- 
tion during acute myocardial infarction (MI). The dephosphorylation of Cx43 decreases gap junction conduction, which produces the substrate for reentrant arrhythmia. Propofol treatment preserved Cx43 phosphorylation during acute myocardial ischemia, and this might protect the heart from serious ventricular arrhythmias during acute coronary occlusion ${ }^{[54]}$. However, one study showed that the electrical uncoupling correlated with an intercalated disk occurred 10-15 min after ischemia $^{[55]}$. In the study of Hirata et al, most of the severe arrhythmias occurred between 5 and $10 \mathrm{~min}$ in all groups ${ }^{[54]}$. As such, the importance of the role played by Cx43 in arrhythmogenesis is debatable.

\section{Propofol and the autonomic nervous system}

The Bezold-Jarish reflex sensitivity is an index of vagal nerve activity. Activation of the Bezold-Jarish reflex by injection of some agents produced a profound reduction in heart rate. It has been postulated that propofol-induced bradycardia may be related to the Bezold-Jarish reflex. Vincze ${ }^{[56]}$ and Ebert ${ }^{[57]}$ indicated that propofol lowered the Bezold-Jarish reflex sensitivity, but other researches indicated that the cause of acute bradycardia after propofol administration did not involve the Bezold-Jarish reflex in humans ${ }^{[58]}$ or rabbitsv ${ }^{[59]}$.

Whether the block of cardiac conduction by propofol is due to direct or indirect effects by the autonomic nervous system is controversial. Ikeno ${ }^{[60]}$ reported that propofol did not affect the cardiac conduction system when the autonomic nervous system was completely blocked. Therefore, it was thought that the conductance change was an indirect effect of propofol. Propofol also reduced the cardiac parasympathetic tone in humans, depending on the depth of hypnosis ${ }^{[61]}$. Propofol could protect the heart from serious ventricular arrhythmias during acute coronary occlusion, but the effect was absolutely blocked by atropine, indicating that the antiarrhythmic effect of propofol was due to a reduction in sympathetic tone leading to a dominance of parasympathetic tone ${ }^{[27]}$. Research showed that propofol suppressed both sympathetic and parasympathetic tone, but the suppression of sympathetic tone was more than that of parasympathetic tone ${ }^{[62,63]}$.

\section{Conclusion}

Though propofol can induce various types of arrhythmias, some of which are severe, the incidence of arrhythmia is relatively rare at clinically relevant concentrations of propofol. Numerous studies conclusively show that propofol has the potential to inhibit arrhythmia. The potential antiarrhythmic mechanisms of propofol include ion channel inhibition, uneven suppression of the autonomic nervous system, and protection of gap junctions during ischemia. The controversies in the field can be attributed in part to the use of different species and experimental conditions and the promiscuous effects of propofol at various concentrations. The currently available data regarding the effects of propofol on arrhythmogenesis are not sufficient. Previous studies mostly focused on normal conditions, but arrhythmias are always induced in abnormal conditions, such as ischemia and electrolyte disturbances. In addition, there is no pharmacogenetic data on the opposing propofol effects at clinically used doses. Available clinical data largely came from sporadic reports rather than largesized, blinded and controlled trials. We believe future studies will expand to these areas to fully characterize the arrhythmic and antiarrhythmic properties of propofol.

\section{Acknowledgements}

This study is granted by National 973 Project (2007CB512008) .

\section{References}

1 Kannan S, Sherwood N. Termination of supraventricular tachycardia by propofol. Br J Anaesth 2002; 88: 874-5.

2 Hermann R, Vettermann J. Change of ectopic supraventricular tachycardia to sinus rhythm during administration of propofol. Anesth Analg 1992; 75: 1030-2.

3 Burjorjee JE, Milne B. Propofol for electrical storm; a case report of cardioversion and suppression of ventricular tachycardia by propofol. Can J Anaesth 2002; 49: 973-7.

4 Mulpuru SK, Patel DV, Wilbur SL, Vasavada BC, Furqan T. Electrical storm and termination with propofol therapy: a case report. Int J Cardiol 2008; 128: e6-8.

5 Miro O, de la Red G, Fontanals J. Cessation of paroxysmal atrial fibrillation during acute intravenous propofol administration. Anesthesiology 2000; 92: 910.

6 Owczuk R, Wujtewicz MA, Sawicka W, Polak-Krzeminska A, SuszynskaMosiewicz A, Raczynska K, et al. Effect of anaesthetic agents on P-wave dispersion on the electrocardiogram: comparison of propofol and desflurane. Clin Exp Pharmacol Physiol 2008; 35: 1071-6.

7 Seki S, Ichimiya T, Tsuchida H, Namiki A. A case of normalization of Wolff-Parkinson-White syndrome conduction during propofol anesthesia. Anesthesiology 1999; 90: 1779-81.

8 Wakita R, Takahashi M, Ohe C, Kohase H, Umino M. Occurrence of intermittent Wolff-Parkinson-White syndrome during intravenous sedation. J Clin Anesth 2008; 20: 146-9.

9 Michaloudis D, Fraidakis O, Kanoupakis E, Flossos A, Manios E. Idiopathic prolonged QT interval and QT dispersion: the effects of propofol during implantation of cardioverter-defibrillator. Eur J Anaesthesiol 1999; 16: 842-7.

10 Kleinsasser A, Loeckinger A, Lindner KH, Keller C, Boehler M, Puehringer F. Reversing sevoflurane-associated Q-Tc prolongation by changing to propofol. Anaesthesia 2001; 56: 248-50.

11 Hanouz JL, Yvon A, Flais F, Rouet R, Ducouret P, Bricard H, et al. Propofol decreases reperfusion-induced arrhythmias in a model of "border zone" between normal and ischemic-reperfused guinea pig myocardium. Anesth Analg 2003; 97: 1230-8.

12 Erb TO, Kanter RJ, Hall JM, Gan TJ, Kern FH, Schulman SR. Comparison of electrophysiologic effects of propofol and isofluranebased anesthetics in children undergoing radiofrequency catheter ablation for supraventricular tachycardia. Anesthesiology 2002; 96: 1386-94.

13 Napolitano CA, Raatikainen MJ, Martens JR, Dennis DM. Effects of intravenous anesthetics on atrial wavelength and atrioventricular nodal conduction in guinea pig heart. Potential antidysrhythmic properties and clinical implications. Anesthesiology 1996; 85: 393402.

14 Alphin RS, Martens JR, Dennis DM. Frequency-dependent effects of propofol on atrioventricular nodal conduction in guinea pig isolated heart. Mechanism and potential antidysrhythmic properties. Anesthesiology 1995; 83: 382-94. 
$15 \mathrm{Wu} \mathrm{MH}$, Su MJ, Sun SS. Comparative direct electrophysiological effects of propofol on the conduction system and ionic channels of rabbit hearts. Br J Pharmacol 1997; 121: 617-24.

16 Warpechowski P, Lima GG, Medeiros CM, Santos AT, Kruse M, Migloransa $\mathrm{MH}$, et al. Randomized study of propofol effect on electrophysiological properties of the atrioventricular node in patients with nodal reentrant tachycardia. Pacing Clin Electrophysiol 2006; 29: 1375-82.

17 Romano R, Ciccaglioni A, Fattorini F, Quaglione R, Favaro R, Arcioni $\mathrm{R}$, et al. Effects of propofol on the human heart electrical system: a transesophageal pacing electrophysiologic study. Acta Anaesthesiol Scand 1994; 38: 30-2.

18 Pires LA, Huang SK, Wagshal AB, Kulkarni RS. Electrophysiological effects of propofol on the normal cardiac conduction system. Cardiology 1996; 87: 319-24.

19 Wu MH, Su MJ, Sun SS. Age-related propofol effects on electrophysiological properties of isolated hearts. Anesth Analg 1997; 84: 964-71.

20 Kamibayashi T, Hayashi Y, Sumikawa K, Yamatodani A, Kawabata K, Yoshiya I. Enhancement by propofol of epinephrine-induced arrhythmias in dogs. Anesthesiology 1991; 75: 1035-40.

21 Rewari V, Kaul H. Sustained ventricular tachycardia in long QT syndrome: is propofol the culprit? Anesthesiology 2003; 99: 764.

22 Douglas RJ, Cadogan M. Cardiac arrhythmia during propofol sedation. Emerg Med Australas 2008; 20: 437-40.

23 Robinson JD, Melman Y, Walsh EP. Cardiac conduction disturbances and ventricular tachycardia after prolonged propofol infusion in an infant. Pacing Clin Electrophysiol 2008; 31: 1070-3.

24 Riezzo I, Centini F, Neri M, Rossi G, Spanoudaki E, Turillazzi E, et al. Brugada-like EKG pattern and myocardial effects in a chronic propofol abuser. Clin Toxicol (Phila) 2009; 47: 358-63.

25 Hug CC Jr, McLeskey CH, Nahrwold ML, Roizen MF, Stanley TH, Thisted RA, et al. Hemodynamic effects of propofol: data from over 25,000 patients. Anesth Analg 1993; 77: S21-9.

26 Aguero Pena RE, Pascuzzo-Lima C, Granado Duque AE, BonfanteCabarcas RA. Propofol-induced myocardial depression: possible role of atrial muscarinic cholinergic receptors. Rev Esp Anestesiol Reanim 2008; 55: 81-5.

27 Morey TE, Martynyuk AE, Napolitano CA, Raatikainen MJ, Guyton TS, Dennis DM. Ionic basis of the differential effects of intravenous anesthetics on erythromycin-induced prolongation of ventricular repolarization in the guinea pig heart. Anesthesiology 1997; 87: 1172-81.

28 Shigemura T, Hatakeyama N, Shibuya N, Yamazaki M, Masuda A, Chen FS, et al. Effects of propofol on contractile response and electrophysiological properties in single guinea-pig ventricular myocyte. Pharmacol Toxicol 1999; 85: 111-4.

29 Hatakeyama N, Sakuraya F, Matsuda N, Kimura J, Kinoshita H, Kemmotsu O, et al. Pharmacological significance of the blocking action of the intravenous general anesthetic propofol on the slow component of cardiac delayed rectifier $\mathrm{K}^{+}$current. J Pharmacol Sci 2009; 110: 334-43.

30 Shibuya N, Higuchi A, Hatakeyama N, Yamazaki M, Ito Y, Momose Y. Effects of propofol on contractility and electrophysiological properties of canine single cardiomyocytes. Masui 1996; 45: 408-14.

31 Puttick RM, Terrar DA. Effects of propofol and enflurane on action potentials, membrane currents and contraction of guinea-pig isolated ventricular myocytes. Br J Pharmacol 1992; 107: 559-65.

32 Kohro S, Hogan QH, Nakae Y, Yamakage M, Bosnjak ZJ. Anesthetic effects on mitochondrial ATP-sensitive $\mathrm{K}$ channel. Anesthesiology 2001; 95: 1435-40.

33 Kamada N, Kanaya N, Hirata N, Kimura S, Namiki A. Cardioprotective effects of propofol in isolated ischemia-reperfused guinea pig hearts: role of $\mathrm{K}_{\text {ATP }}$ channels and GSK-3beta. Can J Anaesth 2008; 55: 595605.

34 Kawano T, Oshita S, Tsutsumi Y, Tomiyama Y, Kitahata H, Kuroda Y, et al. Clinically relevant concentrations of propofol have no effect on adenosine triphosphate-sensitive potassium channels in rat ventricular myocytes. Anesthesiology 2002; 96: 1472-7.

35 Kawano T, Oshita S, Takahashi A, Tsutsumi Y, Tomiyama Y, Kitahata $\mathrm{H}$, et al. Molecular mechanisms of the inhibitory effects of propofol and thiamylal on sarcolemmal adenosine triphosphate-sensitive potassium channels. Anesthesiology 2004; 100: 338-46.

36 Yamada H, Kawano T, Tanaka K, Yasui S, Mawatari K, Takahashi A, et al. Effects of intracellular MgADP and acidification on the inhibition of cardiac sarcolemmal ATP-sensitive potassium channels by propofol. J Anesth 2007; 21: 472-9.

37 Baum VC. Distinctive effects of three intravenous anesthetics on the inward rectifier $\left(I_{K 1}\right)$ and the delayed rectifier $\left(I_{K}\right)$ potassium currents in myocardium: implications for the mechanism of action. Anesth Analg 1993; 76: 18-23.

38 Liu YC, Wang YJ, Wu SN. The mechanisms of propofol-induced block on ion currents in differentiated $\mathrm{H} 9 \mathrm{c} 2$ cardiac cells. Eur J Pharmacol 2008; 590: 93-8.

39 Tamargo J, Caballero R, Gomez R, Valenzuela C, Delpon E. Pharmacology of cardiac potassium channels. Cardiovasc Res 2004; 62: 9-33.

40 Heath BM, Terrar DA. Separation of the components of the delayed rectifier potassium current using selective blockers of $I_{\mathrm{Kr}}$ and $I_{\mathrm{Ks}}$ in guinea-pig isolated ventricular myocytes. Exp Physiol 1996; 81: 587 603.

41 Heath BM, Terrar DA. Block by propofol and thiopentone of the min K current $\left(I_{\mathrm{sK}}\right)$ expressed in Xenopus oocytes. Naunyn Schmiedebergs Arch Pharmacol 1997; 356: 404-9.

42 Buljubasic N, Marijic J, Berczi V, Supan DF, Kampine JP, Bosnjak ZJ. Differential effects of etomidate, propofol, and midazolam on calcium and potassium channel currents in canine myocardial cells. Anesthesiology 1996; 85: 1092-9.

43 Zhou J, Tian M, Zhou ZN. Inhibition of transient outward potassium current in rat ventricular myocytes by propofol. Sheng Li Xue Bao 1997; 49: 99-101.

44 Carnes CA, Muir WW 3rd, Van Wagoner DR. Effect of intravenous anesthetics on inward rectifier potassium current in rat and human ventricular myocytes. Anesthesiology 1997; 87: 327-34.

45 Saint DA, Tang Y. Propofol block of cardiac sodium currents in rat isolated myocardial cells is increased at depolarized resting potentials. Clin Exp Pharmacol Physiol 1998; 25: 336-40.

46 Saint DA. The effects of propofol on macroscopic and single channel sodium currents in rat ventricular myocytes. Br J Pharmacol 1998; 124: 655-62.

47 Baruscotti M, Barbuti A, Bucchi A. The cardiac pacemaker current. J Mol Cell Cardiol 2010; 48: 55-64.

48 Nof E, Antzelevitch C, Glikson M. The contribution of HCN4 to normal sinus node function in humans and animal models. Pacing Clin Electrophysiol 2010; 33: 100-6.

49 Cacheaux LP, Topf N, Tibbs GR, Schaefer UR, Levi R, Harrison NL, et al. Impairment of hyperpolarization-activated, cyclic nucleotide-gated channel function by the intravenous general anesthetic propofol. J Pharmacol Exp Ther 2005; 315: 517-25.

50 Kurokawa H, Murray PA, Damron DS. Propofol attenuates betaadrenoreceptor-mediated signal transduction via a protein kinase C-dependent pathway in cardiomyocytes. Anesthesiology 2002; 96: 688-98.

51 Zhou W, Fontenot HJ, Liu S, Kennedy RH. Modulation of cardiac 
calcium channels by propofol. Anesthesiology 1997; 86: 670-5.

52 Poelzing S, Rosenbaum DS. Altered connexin43 expression produces arrhythmia substrate in heart failure. Am J Physiol Heart Circ Physiol 2004; 287: H1762-70.

53 Saffitz JE, Laing JG, Yamada KA. Connexin expression and turnover: implications for cardiac excitability. Circ Res 2000; 86: 723-8.

54 Hirata N, Kanaya N, Kamada N, Kimura S, Namiki A. Differential effects of propofol and sevoflurane on ischemia-induced ventricular arrhythmias and phosphorylated connexin 43 protein in rats. Anesthesiology 2009; 110: 50-7.

55 Kleber AG, Riegger CB, Janse MJ. Electrical uncoupling and increase of extracellular resistance after induction of ischemia in isolated, arterially perfused rabbit papillary muscle. Circ Res 1987; 61: 271-9.

56 Vincze D, Farkas AS, Rudas L, Makra P, Csik N, Lepran I, et al. Relevance of anaesthesia for dofetilide-induced torsades de pointes in alpha1-adrenoceptor-stimulated rabbits. Br J Pharmacol 2008; 153: $75-89$

57 Ebert TJ. Sympathetic and hemodynamic effects of moderate and deep sedation with propofol in humans. Anesthesiology 2005; 103 :
20-4.

58 Ma D, Chakrabarti MK, Whitwam JG. Propofol, bradycardia and the Bezold-Jarisch reflex in rabbits. Br J Anaesth 1999; 82: 412-7.

59 Cullen PM, Turtle M, Prys-Roberts C, Way WL, Dye J. Effect of propofol anesthesia on baroreflex activity in humans. Anesth Analg 1987; 66: 1115-20.

60 Ikeno S, Akazawa S, Shimizu R, Nakaigawa Y, Ishii R, Inoue S, et al. Propofol does not affect the canine cardiac conduction system under autonomic blockade. Can J Anaesth 1999; 46: 148-53.

61 Kanaya N, Hirata N, Kurosawa S, Nakayama M, Namiki A. Differential effects of propofol and sevoflurane on heart rate variability. Anesthesiology 2003; 98: 34-40.

62 Deutschman CS, Harris AP, Fleisher LA. Changes in heart rate variability under propofol anesthesia: a possible explanation for propofol-induced bradycardia. Anesth Analg 1994; 79: 373-7.

63 Hidaka S, Kawamoto M, Kurita S, Yuge O. Comparison of the effects of propofol and midazolam on the cardiovascular autonomic nervous system during combined spinal and epidural anesthesia. J Clin Anesth 2005; 17: 36-43. 